\section{Birth weight and blood pressure in adolescence}

\section{Studies may be misleading}

EDITOR,-Jean W A Matthes and colleagues found that the blood pressures of 165 adolescents who had had low birth weight were no different from those of a similar number of controls and they concluded that this does not support a link between retarded fetal growth and hypertension. Their findings contrast with eight published studies in pre-adolescent children and four in adults which show that birth weight is inversely related to blood pressure. Differences associated with birth weight are small in childhood but are progressively amplified through life. ${ }^{2}$ Blood pressure is known to track from childhood through into adult life, ${ }^{3}$ but tracking is perturbed during the adolescent growth spurt. ${ }^{4}$ For this reason studies of adolescents are unlikely to contribute importantly to our understanding of the long term effects of fetal growth on blood pressure.

D J P BARKE

Director

C M LAW

MRC Environmental Epidemiology Unit, Epidemiologist

MRC Environmental Epidemio

Southampton SO9 4 XY

1 Matthes JWA, Lewis PA, Davies DP, Bethel JA. Relation between birth weight at term and systolic blood pressure in adolescence. BMF 1994;308:1074-7. (23 April.)

2 Law CM, de Swiet M, Osmond C, Fayers PM, Barker DJP, Cruddas AM, et al. Initiation of hypertension in utero and its amplification throughout life. $B M F$ 1993;306:24-7.

3 Labarthe D, Eissen M, Varas C. Childhood precursors of high blood pressure and elevated cholesterol. Ann Rev Public Healt 1991;12:519-41.

4 Lever A, Harrap S. Essential hypertension: a disorder of growth with origins in childhood. $f$ Hyperten 1992;10:101-20.

\section{Findings could be influenced by stage of puberty}

EDITOR,-Jean W A Matthes and colleagues are to be congratulated on adding to the data about the relation of birth weight and blood pressure that form their carefully designed study, but they do not draw attention to the considerable differences in height and weight between their cases and controls, the former being shorter and "fatter." They state that it was thought "inappropriate" to measure pubertal status, presumably on ethical or practical grounds, but the differences in height

Letters should be no more than 400 words long, should contain a maximum of five references including one to the $B M F$ article to which they refer, and must be typed with double spacing. All authors need to sign the letter and provide their current appointment and address. Please enclose a stamped addressed envelope if you require an acknowledgment. First reports of original research are not published in the letters section. suggest that their cases may not have completed their pubertal growth spurt and this could account to some degree for the negative findings regarding blood pressure. These data are also interesting in themselves in supporting the concept that babies small for dates at term, like runted piglets, may end up shorter and fatter than those of normal birthweight-a habitus that goes with hypertension.

JOHN A DAVIS

Great Shelford

Cambridge CB2 5JE

1 Matthes JWA, Lewis PA, Davies DP, Bethel JA. Relation between birth weight at term and systolic blood pressure in between birth weight at term and systolic blo

\section{Authors' reply}

EDrToR,-We agree with John Davis that the pubertal status of the two groups may be different in the results we report, although we are unaware of studies that show differences in later pubertal development in infants small for dates. If any difference was large enough to be considered important then "age at puberty" would become yet another proxy or even putative causal factor to explain differences in later life. Recognising differences in size between cases and controls, in our linear regression model we adjusted for height, weight, and body mass index. We judged in our study that it would be inappropriate to ascertain pubertal status: the delicate nature of the physical examination required could well have jeopardised recruitment into our study, let alone have posed ethical problems. Initially, details of menarche were collected but the information was very unreliable, most girls having already passed menarche. Similarities with runted piglets are intriguing but we doubt their relevance as our cases were shorter and lighter and had a lower body mass index.

Any perturbation of blood pressure tracking during the adolescent growth spurt would be expected to apply equally to both groups. This would add variation to the data; we took account of this in the study design in the selection of the standard deviation of the sample size calculation. Barker and Law have to argue that there is bias in the perturbation between the two groups for it to be an important factor. They have also to appreciate that, at the age of examination ( 15.6 years for cases, 15.8 years for controls) the puberty growth spurt has been largely completed, especially in girls (who have an earlier growth spurt), who outnumbered boys in our study by nearly $2: 1$.

Ours is the first population based, comparative study to investigate the incidence of low birth weight on later blood pressure by using carefully matched cases and controls. For the reasons we have given we believe our study of adolescents is important to the understanding of links between the fetal environment and blood pressure.

JEAN W A MATTHES Senior registrar in child health PETER A LEWIS Senior lecturer in health informatics D P DAVIES Professor of child health JACQUELINE BETHEL College of Medicine, Cardiff CF4 4XN

\section{Nocturnal ambulatory blood pressure measurement}

EDITOR,-We disagree that the findings of $\mathrm{R} \mathrm{J} \mathrm{O}$ Davies and colleagues should be taken into account as part of clinical and epidemiological interpretation. ${ }^{1}$

The authors assume that the "aroused" ambulatory blood pressure is less accurate than the true physiological pressure. This is self evident but has no clinical relevance, as physiological pressure can never be measured in clinical practice. They also assume that the arousal response is an artefactual source of error. However, recent evidence suggests that such a rise is associated with poor outcome. ${ }^{2}$ Indeed an increased vascular reactivity depends on this arousal. Furthermore, arousal by ambulatory measurement is likely to be less than arousal induced by conventional measurement, because serial mesurements will remove the "white coat" effects.

It is incorrect for the authors to infer from their work that "the blood pressure recorded by ambulatory machines at night may underestimate to variable degrees the reduction in the blood pressure during sleep." The absolute measurement during sleep may be lower, but the reduction may not be underestimated. This is because an equal, if not greater, arousal to blood pressure measurement could occur during the day: If it can be assumed that arousal caused by a measurement is greater when awake than when asleep, the nocturnal reduction during sleep will be overestimated when absolute blood pressure is considered.

Outcome data to date is based on awake conventional blood pressure measurements. It may be that night reading will be a better predictor of outcome as they allow as near a basal state as is practical by reducing the arousal response to a minimum. Until large studies relating nocturnal readings to outcome are performed the best time to take a blood pressure will remain unknown.

ANDREW SHENNAN Lecturer in obstetrics and gynaecology MICHAEL DE SWIET

Institute of Obstetrics and Gynaecology, Royal Postgraduate Medical School, Queen Charlotte's and Chelsea Hospital London W6 0XG

ADEN HALLIGAN Lecturer in obstetrics and gynaecology Department of Obstetrics and Gynaecology,

University of Leicester,

Leicester Royal Infirmary,

Leicester LE2 7LX

1 Davies RJO, Jenkins N, Styradling J. Effect of measuring ambulatory blood pressure on sleep and on blood pressure during sleep. $B M T^{2}$ 1994;308:820-3. (26 March.)

2 Kuwajima I, Suzuki Y, Fujisawa A, Kuramoto K. Is white coat hypertension innocent? Hypertension 1991;22:826-31.

\section{Racial differences and hypertension}

EDrToR,-In their clinic based study of hypertensive patients, Jamil Mayet and colleagues conclude that people of black African descent have more left ventricular hypertrophy than white people for a similar degree of hypertension.' They state that reported duration of hypertension was similar in black and white people, but do not fully 